\title{
Taiwan beckons researchers back from US
}

Hsinchu, Taiwan. Chinese scientists attracted back from the United States are expected to drive the expansion plans of Taiwan's highly successful science-based industrial park in Hsinchu as it enters its third phase of development.

Over the past ten years, nearly 150 companies from Taiwan, the United States, Europe and elsewhere in Asia have set up shop in the science park, which is administered by the government's National Science Council (NSC). Hundreds of Taiwanese scientists and engineers have returned from the United States to set up businesses.

Most activity so far has been in computer and telecommunications related enterprises. Annual sales are about to exceed NT\$100 billion (US $\$ 3.7$ billion). The park, about 60 miles southwest of Taipei, employs 28,000 people, more than 2,000 of whom hold doctorates or masters' degrees in science and engineering. Many of the junior employees have been trained at two universities close to the science park, National Chiao Tung University and National Tsing Hua University.

The nearby Industrial Technology Research Institute (ITRI), funded by the Ministry of Economic Affairs, has provided several spin-off companies and talented researchers. But most of the leaders of companies are what Steve Hsieh, directorgeneral of the park administration, jokingly calls "CEOs" — or "Chinese Entrepreneurs from Overseas" - coming mainly from

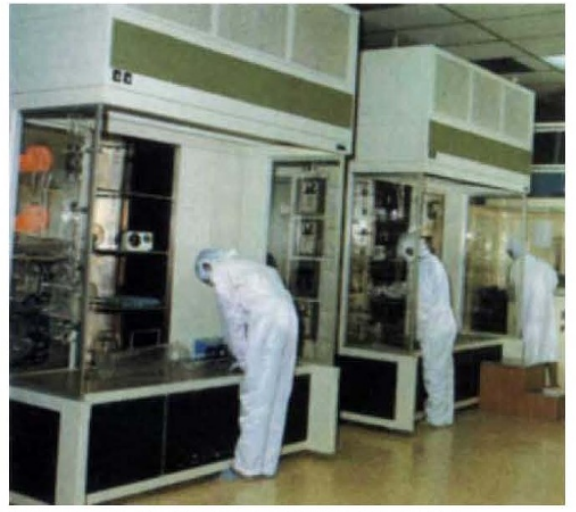

Integrated circuit manufacturing in Hsinchu owes much to Silicon Valley.

\section{California's Silicon Valley.}

The NSC administration rents out land and buildings in the park and helps companies to cope with the red tape involved in setting up and operating a company in Taiwan. Tax incentives are offered in the first few years of operation, as well as financial support for research and development.

The park administrators also showed foresight in establishing from the outset in 1983 a bilingual school for the children of scientists returning from the United States and elsewhere in the West. In this regard, Hsinchu is far ahead of Tsukuba science city in Japan, which after 20 years still has only a tiny privately run international school.

The NSC provides competitive grants of

\section{Synchrotron goes in search of users}

Hsinchu, Taiwan. As the administrators of Taiwan's science park turn their attention to biotechnology (see above), the country's physicists are expressing pride in their first synchrotron, now entering the final stages of commissioning at the new Synchrotron Radiation Research Center in the park.

The achievement is impressive. A country with no experience in building synchrotrons has constructed a sophisticated thirdgeneration machine and reached its operational targets a few months after tests began last April. In August, the synchrotron exceeded its target of a beam current of 200 milliamps, reaching $226 \mathrm{~mA}$, and achieved a beam life of more than five hours.

It is Asia's first such machine. There are more powerful third-generation synchrotrons in the United States and Europe, but Taiwan's has begun operation well before South Korea and Japan bring their first thirdgeneration machines on line.

The big question now is who is going to use the $1.3 \mathrm{GeV}$ machine. The vast circular hall surrounding the US\$110-million synchrotron is largely empty. There is room for
44 beam lines. But at present only three are being operated by a handful of researchers.

None of the integrated circuit manufacturers in the park has expressed interest in using the facility. And, even though training programmes are under way, there are only a limited number of scientists in Taiwan capable of using such machines.

Yuen-Chung Liu, director of the centre, is confident that scientists from overseas will come to use the machine once commissioning has been completed over the next few months, and the capabilities of the machine have become clear.

For example, Liu - who has spent much of his life in Japan - expects scientists building the Spring-8 synchrotron in western Japan to use Hsinchu until their more powerful machine comes on line later this decade.

But many Taiwanese question the value of this investment at a time when funding for research is being squeezed by government spending on new public construction works. To prove its worth, the centre hopes it will be able to draw in users quickly from overseas, as well as from Taiwan itself. up to NT $\$ 5$ million to fund up to 50 per cent of research and development projects carried out by companies. About a quarter of the companies in the park receive such grants each year. This year, the government introduced new incentives to encourage research on 'strategic' products that will increase Taiwan's competitiveness in world markets. Companies have so far applied for NT $\$ 1.4$ billion for 21 strategic-product development plans.

About 200 hectares of land have been acquired next to the existing 380 hectares of the park for the next phase of development. The first companies are expected to set up shop next year.

It has taken more than two years to win approval for the next phase from the local people. "They now realize the value of the park in attracting other small industries and they want to be located close to the development", says Angela Yao, promotion representative for the park administration. The park intends the next phase to concentrate on biotechnology, in particular the production of vaccines for diseases such as hepatitis that are common in Taiwan, as well as medical equipment and food products.

It is not yet clear where the necessary researchers will come from. Taiwan's domestic pharmaceutical companies are weak and have no significant research and development base. In this regard the situation is different from that for integrated circuits, where ITRI provided a ready source of talent and several spin-off companies.

But there is a huge reservoir of bioscientists of Chinese origin in the United States, a pool of talent which the park will no doubt try to tap. Cheng-Wen Wu, director of the Institute of Biomedical Sciences of Academia Sinica in Taipei - who himself returned from the United States - estimates there may be as many as 5,000 such Chinese bioscientists in the United States.

David Swinbanks

\section{Chinese institute appoints new director}

Peking. After the first ever international competition for a top scientific appointment (see Nature 364, 474; 1993), the Chinese Academy of Sciences has announced that the new director of the Institute of Geophysics is to be $\mathrm{Xu}$ Wen-Yue, a research professor at the institute.

Thirty candidates applied for the post when it was advertised earlier this year, a response to growing pressure on the country's research institutions to reform their rigid personnel policies. Xu Wen-Yue was selected from a short-list of four, after consultation with the staff at the institute. You Qin Li 